\title{
PRÁTICA MEDINDO O TEOR DE UMIDADE DE ALIMENTOS
}

\section{Lucyelen Costa Amorim 1 Mayara Cazadini Carlos ${ }^{2}$ Adriana de Medeiros Marcolano Thebas ${ }^{3}$}

Resumo: O teor de umidade é uma das medidas mais importantes utilizadas na análise de alimentos. Em geral, a determinação de umidade, que parece um método simples, torna-se complexo em função da exatidão e precisão dos resultados. O objetivo desse estudo foi determinar o teor de umidade presente em três amostras diferentes: amendoim, laranja e chuchu e estudar um dos métodos para determinação do teor de umidade. Inicialmente as amostras foram cortadas e o cadinho vazio pesado em balança analítica. O cadinho contendo cada amostra foi pesado novamente e depois levado para estufa conforme o método utilizado. Foram realizadas duas repetições para cada amostra. Os resultados mostraram maior quantidade de água presente na laranja e no chuchu quando comparados com o amendoim. Tais resultados estão conforme literatura pesquisada.

Palavras-chave: Água; Alimento; Umidade.

\footnotetext{
1 Ciências Biológicas, Instituto Federal do Espírito Santo - Campus Alegre, Brasil. E-mail: lucyelen_amorim@hotmail.com.br.

2 Ciências Biológicas, Instituto Federal do Espírito Santo - Campus Alegre, Brasil. E-mail: may_cazadini@hotmail.com.

${ }^{3}$ Letras, Faculdade de Filosofia Ciências e Letras de Alegre, Brasil. E-mail: marcolano20@hotmail.com.
} 